\title{
BAFF inhibition does not significantly impair immunization responses in patients with rheumatoid arthritis
}

\author{
Clifton O. Bingham III*, Kevin L. Winthrop², Lili Yang ${ }^{3}$, Chin Lee ${ }^{3}$ and Wendy J. Komocsar ${ }^{3}$
}

Vaccination remains an important strategy in the care of autoimmune disease patients. Patients with rheumatoid arthritis (RA) are at increased risk for infection due to disease-induced immune dysregulation; however, vaccine efficacy can be impaired by concomitant immunomodulators $[1,2]$. Tabalumab is a human monoclonal antibody that neutralizes both soluble and membrane-bound B-cell activating factor (BAFF) [3] and was previously investigated for the treatment of RA and systemic lupus erythematosus. While tabalumab development was discontinued following insufficient efficacy observed in phase $3 \mathrm{RA} /$ systemic lupus erythematosus studies, other BAFF pathway drugs are approved for (belimumab) or being investigated in (atacicept, briobacept) other autoimmune indications, and BAFF bi-specific molecules are in development. Given the importance of immunizations to decrease infection risk in autoimmune diseases and the potential for BAFF antagonists to affect responses, we wished to share data from a tabalumab vaccine substudy in RA.

Patients with RA on background methotrexate (MTX) therapy received either a $240 \mathrm{mg}$ loading dose followed by $120 \mathrm{mg}$ of tabalumab monthly (120/Q4W), $180 \mathrm{mg}$ loading dose followed by $90 \mathrm{mg}$ of tabalumab every bi-weekly (90/ Q2W), or placebo, and were vaccinated with tetanus, diphtheria, acellular pertussis vaccine $(\mathrm{TDaP})$ and 23-valent pneumococcal polysaccharide (PPSV-23) 24 weeks after drug start. A study flow chart shows this in more detail (Additional file 1). Detailed patient demographic information and study methods are included as Additional file 2
(Methods and Supplemental Table 1). The study protocol was approved by the local institutional review boards in accordance with the Declaration of Helsinki and applicable laws, and all patients provided voluntary written informed consent.

\section{Findings}

Sixty-nine patients completed the vaccine substudy; the substudy was part of a larger 52-week study [4]. Expected reductions in total and naïve $B$ cells and increases in memory B cells were observed (Fig. 1). Total immunoglobulins (Ig) were significantly reduced compared with placebo (Additional file 3). Immunization response data are presented in Table 1. More patients achieved an adequate tetanus IgG response (fourfold or greater increase from baseline) in the 120/Q4W group compared with 90/Q2W or placebo, and the 90/Q2W group was not significantly different from placebo. Further, tabalumabtreated patients had similar responses as placebo in the development of total pneumococcal IgG (twofold or greater increase from baseline). Pre-existing immunity to measles and mumps was also not affected by tabalumab (Supplemental Table 2 in Additional file 2).

Overall this study shows that treatment with tabalumab for 24 weeks did not significantly affect the response to protein or polysaccharide vaccines in RA patients despite expected reductions in B cells and total immunoglobulins.

\footnotetext{
* Correspondence: cbingha2@jhmi.edu

'Division of Rheumatology, Johns Hopkins University School of Medicine, 5200 Eastern Avenue, Mason F. Lord Center Tower Room 404, Baltimore, MD 21224, USA

Full list of author information is available at the end of the article
} 


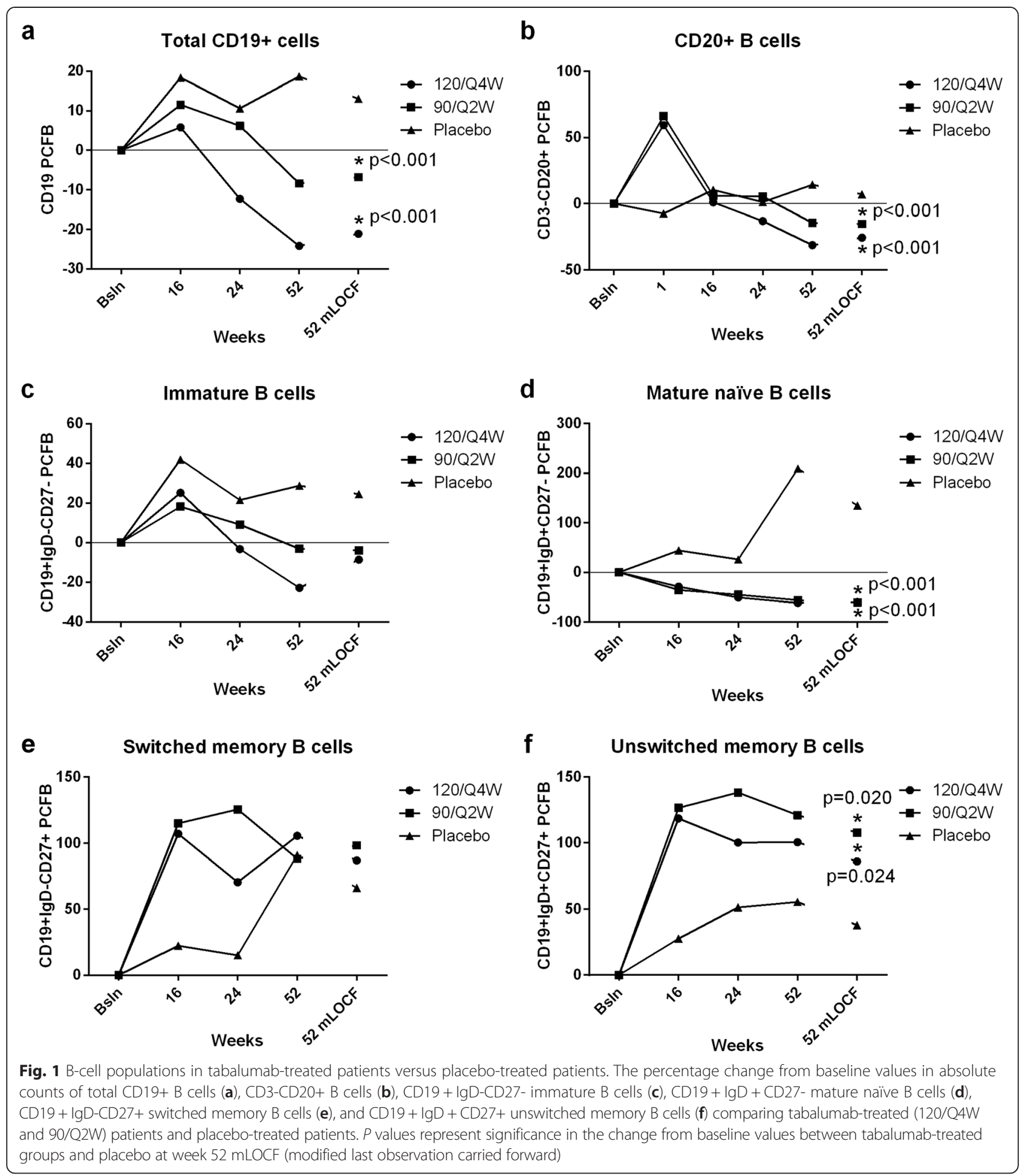


Table 1 Week 28 (4 weeks post-vaccination) tetanus and pneumococcal antibody immunization responses following 24 weeks of tabalumab treatment

\begin{tabular}{|c|c|c|c|c|c|}
\hline & \multirow[t]{2}{*}{ 120/Q4W } & \multirow[t]{2}{*}{ 90/Q2W } & \multirow[t]{2}{*}{ Placebo } & \multicolumn{2}{|c|}{$P$ value versus placebo } \\
\hline & & & & 120/Q4W & 90/Q2W \\
\hline Tetanus IgG antibody response & $n=21^{a}$ & $n=30^{\mathrm{a}}$ & $n=17^{\mathrm{a}}$ & & \\
\hline $\begin{array}{l}\text { Number of patients with } \geq 4 \text {-fold titer increase } \\
\text { where baseline titers } \geq 0.1 \mathrm{IU} / \mathrm{ml}^{\mathrm{b}}(\%)\end{array}$ & $17(81.0)$ & $13(43.3)$ & $10(58.8)$ & 0.167 & 0.371 \\
\hline $\begin{array}{l}\text { Number of patients with } \geq 2 \text {-fold titer increase } \\
\text { where baseline titers } \geq 0.1 \mathrm{IU} / \mathrm{ml}^{\mathrm{b}}(\%)\end{array}$ & $19(90.5)$ & $19(63.3)$ & $10(58.8)$ & 0.051 & 0.766 \\
\hline GMT pre-vaccination baseline (95 \% Cl) & $0.301(0.182,0.498)$ & $0.491(0.280,0.861)$ & $0.341(0.163,0.711)$ & & \\
\hline GMT 4 weeks post-vaccination ( $95 \%$ Cl) & $3.495(1.469,8.315)$ & $2.216(1.151,4.267)$ & $1.963(0.674,5.713)$ & $0.263^{c}$ & $0.423^{c}$ \\
\hline Total pneumococcal lgG antibody response & $n=21^{a}$ & $n=31^{\mathrm{a}}$ & $n=17^{\mathrm{a}}$ & & \\
\hline $\begin{array}{l}\text { Number of patients with } \geq 2 \text {-fold titer increase } \\
\text { where baseline titers } \geq 4 \mathrm{mg} / \mathrm{L}^{\mathrm{b}}(\%)\end{array}$ & $15(71.4)$ & $23(74.2)$ & $13(76.5)$ & $>0.999$ & $>0.999$ \\
\hline GMT pre-vaccination baseline (95 \% Cl) & $61.78(46.30,82.42)$ & $63.77(50.06,81.23)$ & $52.53(36.33,75.95)$ & & \\
\hline GMT post-vaccination (95 \% Cl) & $235.62(150.97,367.72)$ & $220.81(147.19,331.26)$ & $213.04(121.83,372.52)$ & $0.835^{c}$ & $0.563^{c}$ \\
\hline
\end{tabular}

Cl confidence interval, GMT geometric mean titer, lg immunoglobulin, 120/Q4W $120 \mathrm{mg}$ tabalumab every 4 weeks, 90/Q2W 90 mg tabalumab every 2 weeks ${ }^{\mathrm{a}}$ The $\mathrm{n}$ values represent the number of patients immunized with vaccine and a baseline and a 28 week antibody titer

${ }^{\mathrm{b}}$ Or a titer of $\geq 0.2 \mathrm{IU} / \mathrm{ml}$ for patients with baseline titers $<0.1 \mathrm{IU} / \mathrm{ml}$ (tetanus) or $\geq 6 \mathrm{mg} / \mathrm{L}$ for patients with baseline titers $<4 \mathrm{mg} / \mathrm{L}$ (pneumococcus)

${ }^{c} P$ value based on change from baseline log transformed data; rather than providing log transformed titers, we present geometric mean titers as this is the standard way to report these data

\section{Additional files}

Additional file 1: Supplemental Fig. 1. Flowchart for study design. Figure showing study design, treatment groups, and timing of immunizations and assessments. (TIF $235 \mathrm{~kb}$ )

Additional file 2: Methods, Supplemental Table 1, Supplemental Table 2, References. Methods: Description of patient population, study design, endpoints, and analyses. Supplemental Table 1. Baseline demographics and disease characteristics of study groups. Supplemental Table 2. Geometric mean titers of measles and mumps lgG. References for Methods. (DOCX $30 \mathrm{~kb}$ )

Additional file 3: Supplemental Fig. 2. Immunoglobulin levels in tabalumab-treated patients versus placebo-treated patients. (TIF $111 \mathrm{~kb}$ )

\section{Abbreviations}

BAFF: B-cell activating factor; Ig: Immunoglobulin; MTX: Methotrexate; RA: Rheumatoid arthritis.

\section{Competing interests}

COB and KLW have served as consultants to Eli Lilly and Company. WJK, LY, and $\mathrm{CL}$ are employees of and own stock or stock options in Eli Lilly and Company.

\section{Authors' contributions}

All authors meet all authorship requirements and provided critical input and approval of this communication.

\section{Author details}

${ }^{1}$ Division of Rheumatology, Johns Hopkins University School of Medicine, 5200 Eastern Avenue, Mason F. Lord Center Tower Room 404, Baltimore, MD 21224, USA. ${ }^{2}$ Divisions of Infectious Diseases, Public Health, and Preventive Medicine, Oregon Health \& Science University, 3375 SW Terwilliger Blvd, Portland, OR 97239, USA. ${ }^{3}$ Eli Lilly and Company, Indianapolis, IN 46285, USA.

Published online: 30 November 2015

\section{References}

1. Doran MF, Crowson CS, Pond GR, O'Fallon WM, Gabriel SE. Frequency of infection in patients with rheumatoid arthritis compared with controls: a population-based study. Arthritis Rheum. 2002;46:2287-93. doi:10.1002/art. 10524.

2. Gelinck LB, van der Bij AE, Visser LG, Huizinga TW, van Hogezand RA, Rijkers GT, et al. Synergistic immunosuppressive effect of anti-TNF combined with methotrexate on antibody responses to the 23 valent pneumococcal polysaccharide vaccine. Vaccine. 2008;26:3528-33. doi:10. 1016/j.vaccine.2008.04.028

3. Manetta J, Bina H, Ryan P, Fox N, Witcher DR, Kikly K. Generation and characterization of tabalumab, a human monoclonal antibody that neutralizes both soluble and membrane-bound B-cell activating factor. J Inflamm Res. 2014;7:121-31. doi:10.2147/JIR.S67751.

4. Smolen JS, Weinblatt ME, van der Heijde D, Rigby WF, van Vollenhoven R, Bingham CO, et al. Efficacy and safety of tabalumab, an anti-B-cell-activating factor monoclonal antibody, in patients with rheumatoid arthritis who had an inadequate response to methotrexate therapy: results from a phase III multicentre, randomised, double-blind study. Ann Rheum Dis. 2015;74(8): 1567-70. doi:10.1136/annrheumdis-2014-207090. 